\title{
Research on Calculation Method of Power Supply Radius Based on Voltage Deviation in Rural Power Network
}

\author{
Ning Wang \\ School of Electric \& Electronic Engineering, north China electric power university, Baoding 071003, \\ China \\ ninglucy_1982@163.com
}

\begin{abstract}
Keywords: load density, annual cost, voltage excursion, power supply radius, power factor, constrained optimization problem.
\end{abstract}

\begin{abstract}
A mathematical method for working out the power supply radius of rural network is proposed based on voltage deviation. It is a nonlinear constrained optimization model with the objective function to minimize the annual cost per $\mathrm{km} 2$ and the constraint to voltage deviation that 'The rural electric network construct and reconstruct technical guide' dictates. The constraint includes two conditions, one is at the end of lines under the maximal load, and the other is at the header point of lines under the minimal load. The cost of reactive compensation device is considered for the first time. The results including power supply radius and power factor can be regarded as technical and economical index, and they will be helpful to construct and reconstruct the rural power network.
\end{abstract}

\section{Introduction}

Power supply radius is an important technical index on design planning and operation management of rural power network, which affects the structure of power grid, power loss, voltage quality and the network economic operation etc. How to calculate the reasonable power supply radius, which can make the power supply cost of power grid is minimal, becomes a significant research topic. The now available mathematical methods about the power supply radius can be divided into the following categories: 1) taking the annual operation cost as the objective function to solve the power supply radius $[1-3] ; 2)$ the objective function includes the engineering investment and operation cost [4-5]; 3) The power loss or voltage deviation of the transmission line is used as the controlled variable to determine the supply radius [6]. Based on the above research, the relationship between the radius of the supply and the annual calculation cost is studied in this paper. The objective function includes the construction investment, maintenance operation cost and power loss expense of the network, and the allowable deviation of the voltage prescribed in 'The rural electric network construct and reconstruct technical guide' (hereinafter referred to as the guideline) is the restriction variable. The relevant cost of reactive power compensation devices are calculated for the first time, and the final results include not only the values of the power supply radius but also the power factor of different voltage grade in power network.

\section{Basic Idea of Constructing Mathematical Model}

\subsection{Data Acquisition and Processing.}

The data of this paper is based on survey statistics. Firstly, data of the area being studied should be collected. And the data includes the planning power supply area of the related county, the maximum load, maximum load utilization hours, substation capacity of different voltage grade, number of transformers, types of conductors, the cost of different capacity transformer substations, different types of conductors and reactive power compensation device.

Apply computer to data processing and obtain regression equations. And the equations represent the relationship between the substation capacity and investment, the line investment and cross 
sectional area, as well as the reactive power compensation devices investment and compensation capacity etc.

\subsection{Construction Principles}

In order to make the analysis of the problem of universal significance, the assumed condition as follows:

The designed area of rural power supply is about round, and electrical source is located the center of the designed region.

Load is evenly spaced according to the power supply area.

The substation and its outlet are looked upon as a unit.

\section{Establishment of Mathematical Model}

\subsection{Objective Function}

In this paper, the annual cost of the power supply area is calculated as the result of mathematical function, and the expressions as follows:

$\min F_{0}=F_{d}+F_{v}+F_{s}$

In the above formula, $F_{0}$ represents the annual calculation cost of unit power supply area; $F_{d}$ represents the annual value of the construction and the investment of unit power supply area; $F_{v}$ represents the cost of maintenance and operation of unit power supply area; $F_{s}$ represents the power loss cost of unit power supply area; The variables of $F_{d}$ and $F_{v}$ are proportional to the investment value of unit power supply area[7].

Transformers and lines are the main equipment in rural power network. In this paper, the reactive power compensation devices are included. The next step is to build the investment and the power loss expense model of the substation, the line and the reactive power compensation devices.

\subsection{Model of the Investment and the Power Loss Expense}

\section{Model of Substation Investment}

The relationship between the total investment and the capacity of the substation is approximately linear. So the substation investment model can be described by the function as follows:

$$
\left[Z_{B}\right]=B_{1} / L^{2}+B_{2} \sigma
$$

In the above function, $B_{1}=a / \pi, B_{2}=b K_{P}$. The variable $a$ represents the cost which is not related to the substation capacity. The variable $b$ represents the cost which is related to the substation capacity. The variable $K_{P}$ is the ratio between capacity and load. $L$ is the power supply radius. $\sigma$ is the load density.

Model of Line Investment

The relationship between the comprehensive line investment per $\mathrm{km}$ and the shape size is approximately linear. So the line investment model can be described by the function as follows:

$$
\left[Z_{X}\right]=B_{3} \sigma L
$$

In the above function, $B_{3}=K_{P}\left(c+d S_{j}\right) /\left(\sqrt{3} J S_{j} U_{N}\right)$. The variable $c$ represents the cost which is not related to the line shape size. The variable $d$ represents the cost which is related to the line shape size. The variable $S_{j}$ is the line shape size, $J$ is the current density and $U_{N}$ is line rated voltage.

Model of Reactive Power Compensation Device Investment

The reactive power compensation devices investment includes two parts, one is the substations and the other is the line's. The former one is included in the investment of substation, so in this paper, it is only considered the investment of the medium voltage lines' compensation devices. The invest model can be described by the function as follows:

$$
\left[Z_{W}\right]=B_{4} \sigma-B_{5} \sigma \operatorname{tg} \varphi
$$


And $B_{4}=k_{b} \operatorname{tg} \varphi_{1}, B_{5}=k_{b}$. The variable $k_{b}$ represents the comprehensive cost of the compensator per capacity. The variables $\varphi_{1}$ and $\varphi$ represent the power factor angle without and with the compensator.

Power Loss Cost Model of Substation

Mathematical expression is as follows:

$\left[F_{B}\right]=B_{6} \sigma$

And $B_{6}=\left(\Delta P_{0} t+\Delta P_{k} \tau_{1}\right) \beta K_{p}$. The variables $\Delta P_{0}$ and $\Delta P_{\mathrm{k}}$ represent the no-load loss and load loss of transformer per $\mathrm{kVA}$. The variables $\mathrm{t}, \tau_{1}$ and $\beta$ represent annul operation hours of transformer, annual maximum load loss hours of transformer and electricity price.

Power Loss Cost Model of Line

Mathematical expression is as follows:

$\left[F_{X}\right]=B_{7} \sigma L\left(1+\operatorname{tg}^{2} \varphi\right)$

In the above function, $B_{7}=\left(\sqrt{3} J S_{j} r k_{1} \beta \tau_{2}\right) \times 10^{-3} /\left(k_{p} U_{N}\right)$. The variable $r$ represents the resistance of line per $\mathrm{km}$. The variable $k_{1}$ represents the power loss distribution coefficient of line. And the variable $\tau_{2} r$ represents the annual maximum load loss hours of the line.

Power Loss Cost Model of Reactive Power Compensation Device

Mathematical expression is as follows:

$\left[F_{W}\right]=B_{8} \sigma-B_{9} \sigma \operatorname{tg} \varphi$

In the above function, $B_{8}=\beta \operatorname{tg} \varphi_{1} \Delta P t_{1}, B_{9}=\beta \Delta P t_{1}$. The variable $\Delta P$ represents the active loss of unit capacity of the compensator. The variable $t_{1}$ represents the annul operation hours of the compensator.

\subsection{Constraint Equations}

The constraint includes two conditions, one is at the end of lines under the maximal load, and the other is at the header point of lines under the minimal load, which depends on the different allowable voltage deviation according to the guideline. Take, for example, the power supply mode of the $110 / 35 / 10 \mathrm{kV}$. In figure $1, \Delta U_{N}$ is the deviation of transformer rated voltage ratio, $\Delta U_{J}$ is the value of transformer tap, $\Delta U_{K}$ is the maximum voltage loss of transformer windings, and $\Delta U_{L}$ is the maximum voltage loss of line. The voltage deviation equations of the $35 \mathrm{kV}, 10 \mathrm{kV}$ and $0.4 \mathrm{kV}$ line terminals are established at the maximum load. The constraint equation of the $35 \mathrm{kV}$ line terminal is as follows:

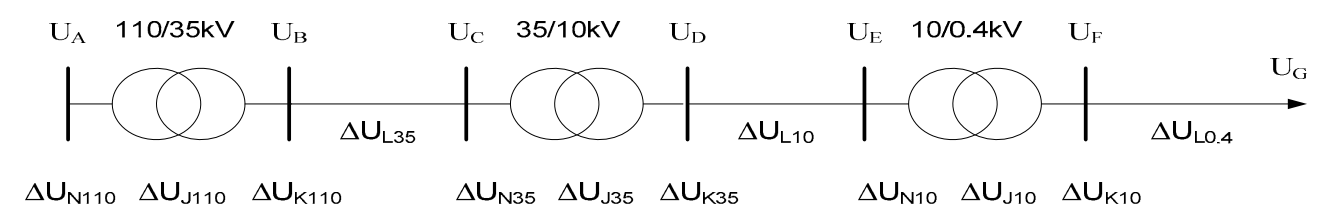

Fig.1 Power network of $110 / 35 / 10 \mathrm{kV}$

$$
\Delta U_{C} \%\left(L_{35}, \operatorname{tg} \varphi_{35}\right)=\Delta U_{A} \%+\Delta U_{N 110} \%+\Delta U_{J 110} \%+\Delta U_{K 110} \%+\Delta U_{L 35} \% \geq-5
$$

In the above equation, $\Delta U_{A} \%$ is the voltage deviation at the upper end of the system? The other equations are as follows:

$$
\left\{\begin{array}{l}
\Delta U_{C} \%\left(L_{35}, \operatorname{tg} \varphi_{35}\right) \geq-5 \\
\Delta U_{E} \%\left(L_{35}, \operatorname{tg} \varphi_{35}, L_{10} \operatorname{tg} \varphi_{10}\right) \geq-7 \\
\Delta U_{G} \%\left(L_{35}, \operatorname{tg} \varphi_{35}, L_{10}, \operatorname{tg} \varphi_{10}\right) \geq-7
\end{array}\right.
$$

The voltage deviation equations at the upper end of $10 \mathrm{kV}$ and $0.4 \mathrm{kV}$ line are established at the minimum load.

$$
\Delta U_{D} \%\left(L_{35}, \operatorname{tg} \varphi_{35}\right)=\Delta U_{A} \%+\Delta U_{N 110} \%+\Delta U_{J 110} \%+\alpha \Delta U_{K 110} \%+\alpha \Delta U_{L 35} \%+\Delta U_{N 35} \%+\Delta U_{J 35} \%+\alpha \Delta U_{K 35} \% \leq 7
$$




$$
\begin{aligned}
& \Delta U_{D} \%\left(L_{35}, \operatorname{tg} \varphi_{35}\right) \leq 7 \\
& \Delta U_{F} \%\left(L_{35}, \operatorname{tg} \varphi_{35}, L_{10}, \operatorname{tg} \varphi_{10}\right) \leq 7
\end{aligned}
$$

In the above equations, $\alpha$ is the loading rate, and $\alpha=0.1$ at the minimum load.

\section{Interpretation of Result}

In this paper, the here point penalty function method is used to solve the problem. Based on survey data in 2004 at somewhere, the results of the 110/35/10kV power grid are in table 1.

Table 1 Values of power supply radius and power factor

\begin{tabular}{cccc}
\hline $\begin{array}{c}\text { Load density } \\
\left(\mathrm{kW} / \mathrm{km}^{2}\right)\end{array}$ & Radius $(\mathrm{km})$ & Power factor & $\begin{array}{c}\text { Recommended values }^{[7]} \text { of } \\
\text { 10kV radius }(\mathrm{km})\end{array}$ \\
\hline 10 & 11.2 & 0.943 & 11 \\
15 & 9.7 & 0.932 & 10 \\
30 & 7.8 & 0.915 & 8 \\
50 & 7.2 & 0.903 & 7 \\
100 & 4.9 & 0.897 & 5 \\
\hline
\end{tabular}

From the results, we can see that with the increase of load density, the radius of supply becomes smaller. The results of $10 \mathrm{kV}$ supply radius are close to the recommended values, that shows the validity of the established model. Meanwhile, with the increase of load density, the power factor decreases gradually. This shows that the operation by reducing the power factor and the compensators' investment is more economical.

\section{Summary}

This paper presents a new method to calculate the radius of the rural power supply based on voltage deviation constraints. With the power supply radius are obtained, the power factors of different voltage level grid are also obtained. The research is of great significance to the construction and reform in the rural power network.

\section{Acknowledgement}

This work is supported by "the Fundamental Research Funds for the Central Universities (2015MS83)".

\section{References}

[1]. Wang Ji-he. On the optimal supply radius of the electrical power distribution system. QINGHAI ELECTRIC POWER. 1999, No. 1, p.1-6.

[2]. Hou li-xia, Zhang Rong-mei, Cao Ju-feng. Discussion on optimal supply radius of the electrical power distribution system. Shanxi Hydrotechnics.2000, No. 136, p.83-84.

[3]. Cao Bing-yuan.Model of Fuzzy Geometric Programming in Economic Power Supply Radius and Optimum Seeking Method. Engineering Science. Vol.3 (2001) No.3, p.52-55.

[4]. Zhang Xiu-ran, Sun Guo-kai, Piao Zai-lin. On the optimal supply radius of the $66 / 10 \mathrm{kv}$ electrical power distribution system. Rural Electrification.1997, No. 11, p.4-6.

[5]. Zhang Xiu-ran, Sun Guo-kai. The Practical Count Method and Analysis of Economic Power Supply Radius. Journal of Shenyang Agricultural University. Vol. 29(1998) No.3, p.249-251.

[6]. Ja Zhi-jie: Feasibility Study on Application of $20 \mathrm{kV}$ Voltage Leval to Middle-Voltage Distribution System (Master of Engineering, Xi'an: Xi'an Jiaotong University, China, 2003). 
[7]. China Electric Power Research Institute. DL/T 5118-2000 Plan design guide for the rural electric power network. Beijing: Popular Tribune Press, 2001. 